\title{
Elevated Plasma Levels of Antimicrobial Polypeptides in Patients with Severe Sepsis
}

\author{
Ingrid Berkestedt ${ }^{\mathrm{a}}$ Heiko Herwald ${ }^{\mathrm{b}}$ Lennart Ljunggren ${ }^{\mathrm{c}}$ Axel Nelson ${ }^{\mathrm{a}}$ \\ Mikael Bodelsson ${ }^{a}$ \\ a Department of Anaesthesiology and Intensive Care, and ${ }^{b}$ Department of Infection Medicine, Lund University, \\ and Lund University Hospital, Lund, and ' Department of Biomedical Laboratory Science, Malmö University, \\ Malmö, Sweden
}

\section{Key Words}

Antimicrobial peptide $\cdot$ Sepsis $\cdot$ Bactericidal/

permeability-increasing protein $\cdot$ Heparin-binding

protein $\cdot$ LL-37 $\cdot$ Defensins

\begin{abstract}
We wanted to investigate if plasma levels of antimicrobial polypeptides (AMPs) are increased in severe sepsis and if they correlate with severity and mortality. Samples were collected from 31 sepsis patients at the intensive care unit. The Sequential Organ Failure Assessment (SOFA) score and 90day mortality were registered, and inflammatory markers and AMP levels were measured by ELISA. A median SOFA score (13) and cardiovascular SOFA score (3) indicated multiorgan failure with severe circulatory derangement, and elevated cytokine levels indicated inflammatory activation. Levels of bactericidal/permeability-increasing protein, heparin-binding protein, $\alpha$-defensins and lactoferrin but not LL37 were elevated in sepsis patients compared with controls. Bactericidal/permeability-increasing protein levels correlated with mortality, with lower levels in survivors. Levels of all AMPs, except LL-37, positively correlated with the cardiovascular SOFA score. In conclusion, levels of several AMPs are increased in sepsis and correlate with circulatory derangement. This probably reflects neutrophil activation as part of an innate immune response.

Copyright @ 2010 S. Karger AG, Basel
\end{abstract}

\section{Introduction}

Sepsis is one of the leading causes of death in the intensive care unit. The pathophysiology includes an uncontrolled inflammatory response resulting from activation of innate immunity, 'the first in line defender' against microbes $[1,2]$. As part of the innate immune system, neutrophil granulocytes play a role in the release of antimicrobial polypeptides (AMPs) [3].

Several authors suggest that AMPs might have a role in the pathophysiology of sepsis [3-6]. This is supported by the observation that the human cathelicidin AMP, LL37 , dilates blood vessels via an interaction with endothelial receptors [7]. Furthermore, levels of bactericidal/permeability-increasing protein (BPI) correlate positively with sepsis severity and mortality $[8,9]$. This may be regarded as contradictory since one would expect that high levels of AMPs would protect the patients from death. Taken together, the role of AMPs in sepsis is all but clear. Therefore, in the present study, we compare the plasma concentration of some AMPs in septic patients with controls and correlate it with the level of inflammatory activation, severity and mortality.

\section{KARGER}

Fax +4161306 1234

E-Mail karger@karger.ch

www.karger.com (c) 2010 S. Karger AG, Basel

$1662-811 X / 10 / 0025-0478 \$ 26.00 / 0$

Accessible online at:

www.karger.com/jin 


\section{Materials and Methods}

\section{Patients}

The local research ethics committee approved the project and informed consent was obtained from patients or next of kin of the unconscious patients. Patients admitted to the intensive care unit of Lund University Hospital, Sweden, because of sepsis between 23 March 2004 and 7 December 2007 were included. All patients fulfilled at least 2 out of 4 criteria for systemic inflammatory response syndrome, had a suspected or verified underlying infection and respiratory and/or circulatory dysfunction requiring intensive care. Therefore, they fulfilled the criteria for severe sepsis or septic shock [10]. Severity of organ dysfunction was defined with the Sequential Organ Failure Assessment (SOFA) score on the basis of measurements during the first $24 \mathrm{~h}$ of admission [11]. The mortality rate within 90 days after inclusion was registered. Controls consisted of patients scheduled for neurosurgery. None of the control patients had ongoing steroid treatment or had been given heparin/heparin-like drugs.

Segments of omental arteries and veins $(0.5-1.5 \mathrm{~mm}$ in diameter) were obtained from 2 patients undergoing abdominal surgery.

\section{ELISA Assays}

Levels of AMPs and interleukins in EDTA plasma were measured by sandwich ELISA as follows: BPI, HyCult biotechnology b.v., detection limit $1.52 \mathrm{ng} \mathrm{ml}^{-1}$; heparin-binding protein (HBP), as previously described [12], detection limit $4.7 \mathrm{ng} \mathrm{ml}^{-1}$; $\alpha$-defensins (HNP1-3), HyCult biotechnology b.v., detection limit 16 pg ml ${ }^{-1}$; interleukin-6 (IL-6), R\&D Systems High Sensitivity ELISAs, detection limit $0.156 \mathrm{pg} \mathrm{ml}^{-1}$; IL-10, R\&D Systems High Sensitivity ELISAs, detection limit $0.78 \mathrm{pg} \mathrm{m}^{-1}$; lactoferrin, HyCult biotechnology b.v., detection limit $2 \mathrm{ng} \mathrm{m}^{-1}$; LL-37, HyCult biotechnology b.v., detection limit $0.10 \mathrm{ng} \mathrm{ml}^{-1}$; myeloperoxidase (MPO), Diagnostics Development, Uppsala, Sweden, detection limit $31 \mathrm{ng}$ $\mathrm{ml}^{-1}$.

\section{Measurements of Procalcitonin, C-Reactive Protein and White Blood Cell Count}

The concentration of procalcitonin in citrate plasma was measured using an immunoluminometric assay kit from BRAHMS Aktiengesellschaft, sensitivity $0.01 \mathrm{ng} \mathrm{ml}^{-1}$. Concentrations of Creactive protein $(\mathrm{CRP})$ in venous blood were measured by routine latex-enhanced immunoturbidimetry (Roche Diagnostics). Routine white blood cell count (WBC) was determined by flow cytometry (Sysmex).

\section{Measurement of Smooth Muscle Force}

Vessel segments were mounted in organ baths for measurements of smooth muscle contraction, as previously described [7]. To 3 of the 6 segments run in parallel, endothelin- 1 was added to give a submaximal contraction. HBP was then added cumulatively in $10 \times$ increments $(0.1 \mathrm{nM}-10 \mu \mathrm{M} ; 1 \mu \mathrm{M}$ corresponding to 37 $\mu \mathrm{g} \mathrm{ml}^{-1}$ ), and resulting changes in smooth muscle tension were registered.

\section{Statistical Analysis}

Data are expressed as the median followed by the 25th and 75th percentile in parentheses when not otherwise indicated. Differences in median plasma levels of AMPs between septic pa-
Table 1. Patient characteristics

\begin{tabular}{|c|c|c|}
\hline & Sepsis & Control \\
\hline Patients & 31 & 25 \\
\hline Age, years & $65(28-87)$ & $64(22-85)$ \\
\hline Male/female & $12 / 19$ & $11 / 14$ \\
\hline Survival rate, $\%$ & 61 & \\
\hline Survival rate, $\mathrm{n}$ & $19 / 31$ & \\
\hline WBC count, $\times 10^{9} \mathrm{l}^{-1}$ & $12(0.2-39)$ & \\
\hline $\mathrm{CRP}, \mathrm{mg} \mathrm{l}^{-1}$ & $196(54-542)$ & \\
\hline Procalcitonin, $\mathrm{ng} \mathrm{ml}^{-1}$ & $39(0.5-445)$ & $0.012(0.003-0.11)$ \\
\hline IL-6, pg ml ${ }^{-1}$ & $2,302(159-494,575)$ & $0.5(0.2-0.5)$ \\
\hline IL-10, pg ml ${ }^{-1}$ & $126(5-2,329)$ & $3.6(0.9-17.0)$ \\
\hline SOFA score & $13(5-18)$ & \\
\hline $\begin{array}{l}\text { Cardiovascular SOFA } \\
\text { score }\end{array}$ & $3(0-4)$ & \\
\hline
\end{tabular}

Data are medians, with range in parentheses.

tients and controls, and between survivors and non-survivors, were assessed with the Mann-Whitney $U$ test. Differences between median levels at inclusion and 4 days later were assessed with the Wilcoxon signed-rank test. Correlations were evaluated using the Spearman rank order correlation. Differences and correlations were considered as statistically significant when $\mathrm{p}<$ 0.05. All data were processed using Sigma Stat for Windows 3.0.1 (SPSS Inc.).

\section{Results}

\section{Patient Characteristics}

Patient characteristics are summarized in table 1. Sex distribution and age were similar in sepsis and control patients. Median procalcitonin, IL-6 and IL-10 levels were higher in the sepsis patients compared with controls $(p<0.001)$. In the sepsis patients, the levels of these inflammation markers had decreased at day 4 compared with the levels at inclusion [procalcitonin: 35 (4.1-85) at inclusion vs. $4.7(0.34-12) \mathrm{ng} \mathrm{ml}^{-1}$ at day $4, \mathrm{p}=0.002$; IL6: 3,785 (1,033-9,992) at inclusion vs. $97(27-225) \mathrm{pg} \mathrm{ml}^{-1}$ at day 4, $\mathrm{p}=0.01$; IL-10: $131(103-299)$ at inclusion vs. 14 (11-23) $\mathrm{pg} \mathrm{m}^{-1}$ at day $4, \mathrm{p}<0.002$. The $\mathrm{WBC}$ varied widely while the CRP level was higher than the laboratory reference level $\left(<3 \mathrm{mg} \mathrm{l}^{-1}\right)$ for all sepsis patients. In sepsis patients, MPO levels were higher than in controls [255 (148-469) vs. $53(48-62) \mathrm{ng} \mathrm{ml}^{-1}$ ] and decreased on day 4 compared with the levels at inclusion. In the sepsis patients, blood culture was positive for Escherichia coli species in 5 patients, Streptococcus pneumoniae species in 

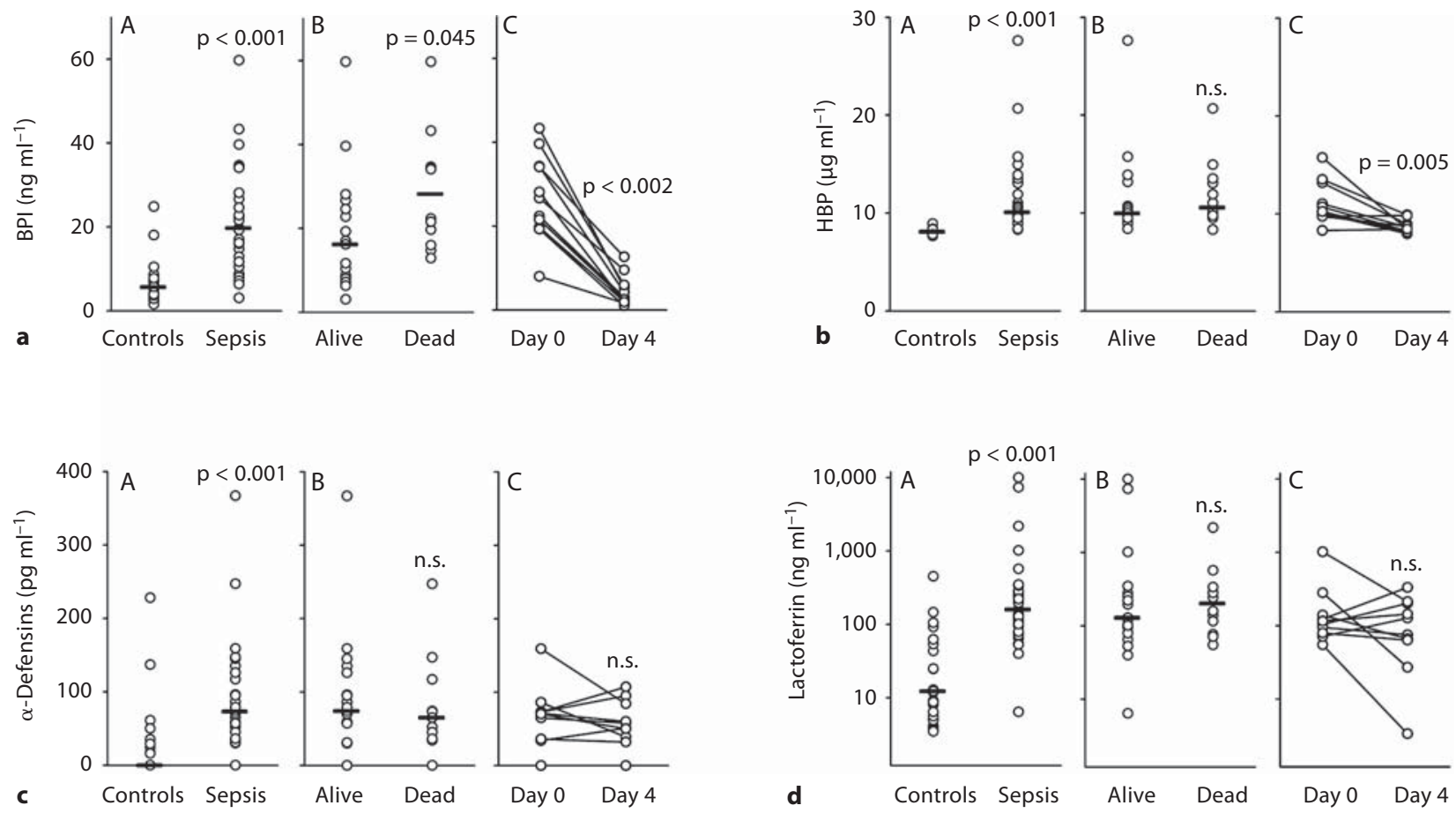

Fig. 1. Plasma levels of BPI (a), HBP (b), $\alpha$-defensins (c) and lactoferrin (d) in patients with severe sepsis and controls. $p$ values refer to statistically significant differences in median levels of sepsis patients compared with controls ( $A, n=25-31)$, between dead or alive sepsis patients at 90 days after admission $(B, n=29-31)$ or of sepsis patients at day 4 compared with the day of admission $(C$, $\mathrm{n}=10-12)$. The circles represent individual patients and the median is indicated with a horizontal line. The Mann-Whitney U test (A, B) or Wilcoxon signed-rank test (C) was used. n.s. = Not significant, $\mathrm{p} \geq 0.05$.
4 patients, enterococcus species in 3 patients, coagulasenegative staphylococci in 2 patients, pseudomonas species in 1 patient and enterobacter species in 1 patient. One of the patients had positive blood culture for both enterococcus and enterobacter species. In 15 of the patients, the blood culture was negative.

\section{AMP Levels}

Median levels of BPI, HBP, $\alpha$-defensins and lactoferrin were higher in sepsis patients compared with controls (fig. 1). In the sepsis patients, the levels of the azurophil granule marker, MPO, correlated with the levels of BPI $(\mathrm{p}<0.01, \mathrm{r}=0.50)$, HBP $(\mathrm{p}<0.001, \mathrm{r}=0.79)$ and $\alpha$-defensins ( $p<0.01, r=0.54)$. The median BPI level was higher in non-survivors than in survivors, while levels of HBP, $\alpha$-defensins and lactoferrin did not correlate with mortality (fig. 1). At day 4, the median BPI and HBP levels were lower than at inclusion while there was no differ- ence in median $\alpha$-defensin or lactoferrin levels at day 4 compared with the levels at inclusion (fig. 1).

HBP at the concentrations tested induced neither contraction nor relaxation in human omental arteries $(\mathrm{n}=2)$ or veins $(n=2)$. A response to HBP was absent regardless whether the segments were pre-contracted by endothelin-1 or not.

The median LL-37 level was similar in sepsis patients and controls. The LL-37 levels of the sepsis patients correlated neither with the levels of the specific granule protein lactoferrin nor with MPO. In the sepsis patient group, the median LL-37 level differed neither between non-survivors and survivors nor between day 4 and inclusion.

\section{Correlation between Levels of AMPs, Mediators of} Inflammation and SOFA Scores

No significant correlation was found between the levels of AMPs and the levels of WBC, procalcitonin, CRP 
or IL-6. However, the IL-10 levels correlated with the levels of HBP $(p<0.01, r=0.58), \alpha$-defensins $(p<0.01, r=$ $0.50)$, lactoferrin $(\mathrm{p}<0.05, \mathrm{r}=0.40)$ and LL-37 $(\mathrm{p}<0.05$, $r=0.39$ ) but not with the levels of BPI. The total SOFA score correlated with the levels of HBP $(p<0.01, r=0.52)$ and $\alpha$-defensins $(\mathrm{p}<0.01, \mathrm{r}=0.49)$ but not with the levels of BPI, lactoferrin and LL-37. The cardiovascular SOFA score correlated with the levels of BPI $(\mathrm{p}<0.05, \mathrm{r}=0.37)$, HBP $(\mathrm{p}<0.001, \mathrm{r}=0.66)$, $\alpha$-defensins $(\mathrm{p}<0.05, \mathrm{r}=0.44)$ and lactoferrin $(\mathrm{p}<0.05, \mathrm{r}=0.39)$ but not with LL-37.

\section{Discussion}

The median plasma levels of cytokines IL- 6 and IL-10 were more than 4,000 and 30 times greater in sepsis patients compared with controls. This indicates a massive inflammatory activation in the sepsis patients, which is supported by the high CRP and procalcitonin levels, as previously reported [13]. The levels of these markers were lower at day 4, illustrating the dynamic course of the condition. All but 1 of the sepsis patients had a cardiovascular SOFA score of 1 or more (median 3), indicating that they suffered from septic shock or severe sepsis based on a failing circulation.

The median level of the azurophil granule protein MPO was 5 times higher in the sepsis patients than in controls, indicating neutrophil activation. Therefore, it was not surprising that the levels of BPI, also present in azurophil granules, were high and correlated with the MPO levels. BPI is an antimicrobial protein selective for Gram-negative bacteria. The level of BPI correlated with mortality, with higher levels in patients not surviving 90 days after inclusion, confirming previous results by Rintala and collegues [9] as well as by Calvano et al. [8]. The results suggest that BPI alone does not protect from death. This is in accordance with the results from a large-scale controlled trial evaluating a recombinant BPI fraction for treatment of meningococcal sepsis in children, which did not show any improvement in survival in the treatment group [14].

HBP, like BPI, is a cationic antimicrobial protein released from the azurophilic granules of neutrophils. However, as opposed to BPI, it displays a broad-spectrum antimicrobial activity against Gram-negative and Grampositive bacteria as well as against fungi [15]. As expected, the HBP levels followed a similar pattern to MPO, BPI and $\alpha$-defensins, also present in azurophilic granules. HBP has been suggested to participate in neutrophilevoked increase in vascular permeability and might in this way contribute to hypovolemia during sepsis [16]. In fact, the levels of HBP correlated strongly with circulatory derangement as reflected in the cardiovascular SOFA score. However, it must be noted that the cardiovascular SOFA score also correlated with the levels of all AMPs measured, except LL-37, as well as with cytokine levels, probably mirroring general activation of innate immunity and degranulation of neutrophils. Thus, the present results neither support nor exclude a role of HBP in the pathophysiology of circulatory failure in clinical sepsis. The increase in vascular permeability induced by HBP involves signaling within the vascular endothelial cells [16]. Therefore, we performed in vitro contraction experiments in order to see if these events could also affect vascular tone. HBP did not induce contraction or relaxation of vascular smooth muscle.

We found that, in line with the other AMPs stored in azurophilic granules, the levels of $\alpha$-defensins are increased in adult sepsis, confirming previous findings in children [17]. However, as opposed to HBP and BPI, the levels remained elevated also at day 4 . This suggests that the clearance of $\alpha$-defensins is lower than for the other AMPs and/or that the production and release persists over a longer time.

The median plasma lactoferrin level was increased more than 10-fold in our adult sepsis patients, confirming previous observations in children [17]. Lactoferrin is stored in the specific granules of neutrophils. The levels of lactoferrin did not correlate with levels of MPO, suggesting that specific and azurophilic granules can be secreted separately during septic conditions. An alternative explanation is a slower turn-over of lactoferrin than MPO, which is supported by our observation of retained levels of lactoferrin at day 4.

LL-37 is stored in the specific granules of neutrophils and released as an 18-kDa pro-peptide, hCAP-18, together with the enzyme proteinase 3 , which immediately cleaves it, giving rise to LL-37 [18]. We did not detect any difference in plasma levels of LL-37 between sepsis patients and controls. This is in accordance with unpublished observations that the levels of hCAP-18/LL-37 do not parallel the disease progress of pneumonia patients $(\mathrm{O}$. Sørensen, pers. commun.). It seems reasonable to assume that hCAP-18 release and subsequent LL-37 production parallel lactoferrin release. Yet, lactoferrin levels are increased in sepsis patients while LL-37 levels are unaltered. In plasma, LL-37 is immediately taken up by lipoproteins [19]. The present results suggest that this is a highly effective LL-37 scavenging mechanism in sepsis patients.

Due to the low rate of positive blood cultures, no reliable subgroup analysis based on the bacterial agent could 
be performed. It must also be noted that the control patients were not critically ill. Thus, it cannot be excluded that the differences observed between these and the sepsis patients could to some degree also depend on the general critical illness and not on sepsis per se.

In conclusion, the plasma levels of all AMPs released from neutrophil azurophilic granules and lactoferrin from specific granules are increased in patients with severe sepsis. The levels generally correlate with the degree of circulatory derangement, both reflecting the fierce inflammatory activation of the condition.

\section{Acknowledgements}

This work was supported by the Swedish Research Council, Grant No. 2004-3874, the Lund University Hospital Research Funds, the Skåne County Council's Research and Development Foundation, the Crafoord Foundation, the LPS Medical Foundation, the Royal Physiographic Society in Lund and the Anna and Edwin Berger Foundation.

\section{References}

1 Cohen J: The immunopathogenesis of sepsis. Nature 2002;420:885-891.

2 Hotchkiss RS, Karl IE: The pathophysiology and treatment of sepsis. N Engl J Med 2003; 348:138-150.

-3 Zasloff M: Antimicrobial peptides of multicellular organisms. Nature 2002;415:389 395.

4 Boman HG: Antibacterial peptides: basic facts and emerging concepts. J Intern Med 2003;254:197-215.

5 Sørensen OE, Borregaard N, Cole AM: Antimicrobial peptides in innate immune responses. Contrib Microbiol 2008;15:61-77.

-6 Ciornei CD, Egesten A, Bodelsson M: Effects of human cathelicidin antimicrobial peptide 1l-37 on lipopolysaccharide-induced nitric oxide release from rat aorta in vitro. Acta Anaesthesiol Scand 2003;47:213-220.

-7 Berkestedt I, Nelson A, Bodelsson M: Endogenous antimicrobial peptide 11-37 induces human vasodilatation. Br J Anaesth 2008 100:803-809.

8 Calvano SE, Thompson WA, Marra MN, Coyle SM, de Riesthal HF, Trousdale RK, et al: Changes in polymorphonuclear leukocyte surface and plasma bactericidal/permeability-increasing protein and plasma lipopolysaccharide binding protein during endotoxemia or sepsis. Arch Surg 1994;129: 220-226. $\checkmark 9$ Rintala E, Peuravuori H, Pulkki K, VoipioPulkki LM, Nevalainen T: Bactericidal/permeability-increasing protein (BPI) in sepsis correlates with the severity of sepsis and the outcome. Intensive Care Med 2000;26:12481251.

10 American College of Chest Physicians/Society of Critical Care Medicine Consensus Conference: definitions for sepsis and organ failure and guidelines for the use of innovative therapies in sepsis. Crit Care Med 1992; 20:864-874.

11 Vincent JL, de Mendonca A, Cantraine F, Moreno R, Takala J, Suter PM, Sprung CL, Colardyn F, Blecher S: Use of the SOFA score to assess the incidence of organ dysfunction/ failure in intensive care units: results of a multicenter, prospective study. Working group on 'sepsis-related problems' of the European Society of Intensive Care Medicine. Crit Care Med 1998;26:1793-1800.

12 Kahn R, Herwald H, Müller-Esterl W, Schmitt R, Sjögren AC, Truedsson L, Karpman D: Contact-system activation in children with vasculitis. Lancet 2002;360:535541.

13 Lam HS, Pak NG: Biochemical markers of neonatal sepsis. Pathology 2008;40:141-148.

14 Levin M, Quint PA, Goldstein B, Barton P, Bradley JS, Shemie SD, Yeh T, Kim SS, Cafaro DP, Scannon PJ, Giroir BP: Recombinant bactericidal/permeability-increasing protein (rBPI21) as adjunctive treatment for children with severe meningococcal sepsis: a randomised trial. rBPI21 Meningococcal Sepsis Study Group. Lancet 2000;356:961967.
15 Gabay JE, Scott RW, Campanelli D, Griffith J, Wilde C, Marra MN, Seeger M, Nathan CF: Antibiotic proteins of human polymorphonuclear leukocytes. Proc Natl Acad Sci USA 1989;86:5610-5614.

16 Gautam N, Olofsson AM, Herwald H, Iversen LF, Lundgren-Åkerlund E, Hedqvist P, Arfors KE, Flodgaard H, Lindbom L: Heparin-binding protein (HBP/CAP37): a missing link in neutrophil-evoked alteration of vascular permeability. Nat Med 2001;7: 1123-1127.

17 Thomas NJ, Carcillo JA, Doughty LA, Sasser $\mathrm{H}$, Heine RP: Plasma concentrations of defensins and lactoferrin in children with severe sepsis. Pediatr Infect Dis J 2002;21:3438.

18 Sørensen OE, Follin P, Johnsen AH, Calafat J, Tjabringa GS, Hiemstra PS, Borregaard N: Human cathelicidin, hCAP-18, is processed to the antimicrobial peptide LL-37 by extracellular cleavage with proteinase 3 . Blood 2001;97:3951-3959.

19 Wang Y, Agerberth B, Löthgren A, Almstedt A, Johansson J: Apolipoprotein A-I binds and inhibits the human antibacterial/cytotoxic peptide LL-37. J Biol Chem 1998;273: 33115-33118. 